\title{
Depth-Selective Study of Surface Crystallization in NANOPERM-Type Alloys
}

\author{
M. Miglierini ${ }^{a, b, *}$, T. HatAla ${ }^{a}$, M. Bujdos̆ ${ }^{c}$ \\ ${ }^{a}$ Institute of Nuclear and Physical Engineering, Faculty of Electrical Engineering and Information Technology, \\ Slovak University of Technology in Bratislava, Ilkovičova 3, 81219 Bratislava, Slovakia \\ ${ }^{b}$ Regional Centre of Advanced Technologies and Materials, Palacky University, 17. listopadu 12, 77146 Olomouc, \\ Czech Republic \\ ${ }^{c}$ Institute of Laboratory Research on Geomaterials, Faculty of Natural Sciences, Comenius University, Mlynská \\ dolina, 84215 Bratislava, Slovakia
}

\begin{abstract}
Evolution of structure and magnetic order is studied in the ${ }^{57} \mathrm{Fe}_{81} \mathrm{Mo}_{8} \mathrm{Cu}_{1} \mathrm{~B}_{10}$ alloy by conversion electron and conversion X-ray ${ }^{57}$ Fe Mössbauer spectrometry. Surface features exhibit differences at both sides of ribbon-shaped samples with respect to the screening depth. In the as-quenched state, traces of magnetite (in addition to bcc-Fe) are revealed only at the wheel side of the ribbon to the depth of about $200 \mathrm{~nm}$. It is present also after annealing up to $510{ }^{\circ} \mathrm{C}$, then it disappears. In deeper regions (down to $1 \mu \mathrm{m}$ ), magnetite is less abundant. At the air side, only bcc-Fe is detected, though the progress of crystallization is more pronounced here than at the wheel side. Vibration properties of the bulk of amorphous and nanocrystalline samples are obtained from experiments of nuclear inelastic scattering of synchrotron radiation using partial densities of phonon states.
\end{abstract}

DOI: $10.12693 /$ APhysPolA.126.56

PACS: 76.80.+y, 75.70.i, 71.55.Jv, 65.80.-g, 63.22.-m, 63.50.-x

\section{Introduction}

Magnetic [1, 2] and thermodynamic [3] properties of NANOPERM alloys are frequently studied by conventional as well as local probe methods that provide information from the whole bulk of the investigated samples. Surface features, however, deserve still closer inspection. Due to diverse quenching conditions at both sides of the ribbons, distinctions in the progress of crystallization, and hence magnetic microstructure can be expected.

In this work, we report on the progress of surface crystallization with depth at both sides of a NANOPERMtype metallic glass. We report also on thermodynamic properties that were recently examined by nuclear inelastic scattering of synchrotron radiation [4].

\section{Experimental details}

${ }^{57} \mathrm{Fe}_{81} \mathrm{Mo}_{8} \mathrm{Cu}_{1} \mathrm{~B}_{10}$ metallic glass was prepared by rapid quenching. Its chemical composition was checked by optical emission spectrometry with inductively coupled plasma (Mo, B) and flame atomic absorption spectrometry $(\mathrm{Fe}, \mathrm{Cu})$. As-quenched and partially crystallized samples were studied by Conversion Electron Mössbauer Spectrometry (CEMS) and Conversion X-ray Mössbauer Spectrometry (CXMS). They provide depth selective information from the subsurface layers to about $200 \mathrm{~nm}$ and $1 \mu \mathrm{m}$, respectively. Bulk sensitive nuclear inelastic

*corresponding author; e-mail: marcel.miglierini@stuba.sk scattering (NIS) spectra were taken at the ESRF ID18 beamline at room temperature. To facilitate CEMS, CXMS, and NIS experiments, iron in the alloys was enriched with the isotope ${ }^{57} \mathrm{Fe}$ to about $50 \%$.

\section{Results and discussion}

CEMS spectra of the as-quenched ribbons in Fig. 1 show traces of bcc-Fe (dark grey) and $\mathrm{Fe}_{3} \mathrm{O}_{4}$ (light grey) at both sides. CXMS proves only bcc-Fe at the wheel side. The central quadrupole doublet indicates a paramagnetic state of the amorphous part of the alloy.

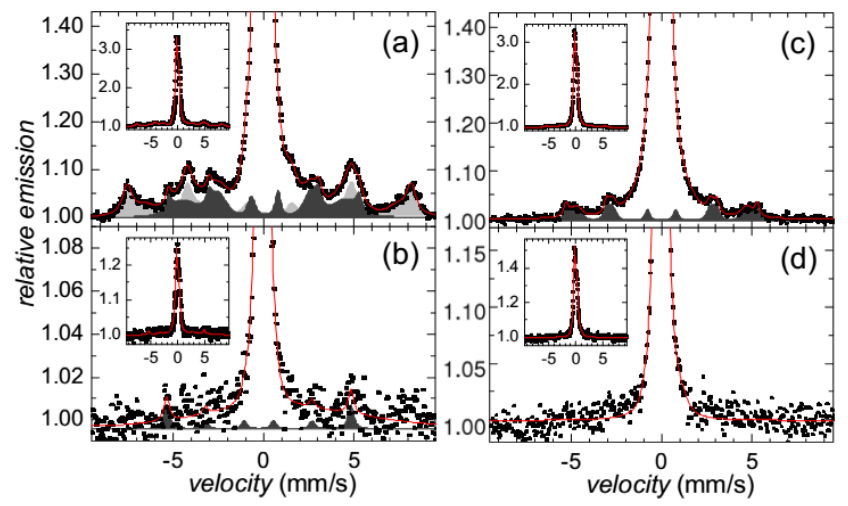

Fig. 1. CEMS (a, c) and CXMS (b, d) spectra of the as-quenched ${ }^{57} \mathrm{Fe}_{81} \mathrm{Mo}_{8} \mathrm{Cu}_{1} \mathrm{~B}_{10}$ alloy recorded from the wheel $(\mathrm{a}, \mathrm{b})$ and air $(\mathrm{c}, \mathrm{d})$ sides. Insets show the full spectra.

After annealing, the quantity of bcc-Fe nanograins has significantly increased namely at the air side. Conse- 
quently, the residual amorphous phase is polarised by exchange interactions among the nanograins. Along with distribution of quadrupole doublets also the magnetically distributed spectral component appears. The surfaces of nanocrystalline bcc-Fe grains are reconstructed by a distribution of magnetic hyperfine fields whereas their bulk is described by narrow six-line subspectra. Magnetite $\left(\mathrm{Fe}_{3} \mathrm{O}_{4}\right)$ spectra are refined by two narrow sextets.

Examples of CEMS and CXMS spectra taken from the wheel side of the samples annealed at $510^{\circ} \mathrm{C}$ and $550{ }^{\circ} \mathrm{C}$ are presented in Fig. 2, relative contributions of the crystalline phases are listed in Table I.
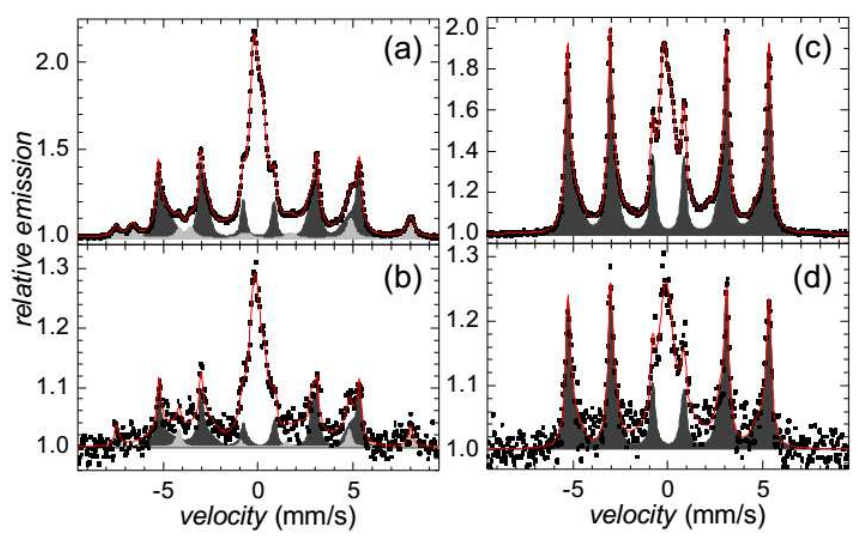

Fig. 2. CEMS (a, c) and CXMS (b, d) spectra recorded from the wheel side of the ${ }^{57} \mathrm{Fe}_{81} \mathrm{Mo}_{8} \mathrm{Cu}_{1} \mathrm{~B}_{10}$ alloy annealed at $510{ }^{\circ} \mathrm{C}(\mathrm{a}, \mathrm{b})$ and $550{ }^{\circ} \mathrm{C}(\mathrm{c}, \mathrm{d})$.

TABLE I

Total amount of crystalline phase (\%) in the ${ }^{57} \mathrm{Fe}_{81} \mathrm{Mo}_{8} \mathrm{Cu}_{1} \mathrm{~B}_{10}$ alloy as derived from Mössbauer spectrometry (error margin is $\pm 1.5 \%$ ). As-quenched sample is denoted by a.q..

\begin{tabular}{c|c|c|c|c|c}
\hline \hline \multirow{2}{*}{ sample } & \multirow{2}{*}{ phase } & \multicolumn{2}{|c|}{ wheel side } & \multicolumn{2}{c}{ air side } \\
\cline { 3 - 6 } & & CEMS & CXMS & CEMS & CXMS \\
\hline \multirow{2}{*}{ a.q. } & bcc-Fe & 12 & 12 & 8 & 0 \\
\cline { 2 - 6 } & $\mathrm{Fe}_{3} \mathrm{O}_{4}$ & 16 & 6 & 7 & 0 \\
\hline \multirow{2}{*}{$370{ }^{\circ} \mathrm{C}$} & $\mathrm{bcc}-\mathrm{Fe}$ & 18 & 16 & 35 & 43 \\
\cline { 2 - 6 } & $\mathrm{Fe}_{3} \mathrm{O}_{4}$ & 14 & 12 & 0 & 0 \\
\hline \multirow{2}{*}{$510{ }^{\circ} \mathrm{C}$} & $\mathrm{bcc}-\mathrm{Fe}$ & 41 & 33 & 59 & 56 \\
\cline { 2 - 6 } & $\mathrm{Fe}_{3} \mathrm{O}_{4}$ & 12 & 8 & 2 & 0 \\
\hline \multirow{2}{*}{$550{ }^{\circ} \mathrm{C}$} & $\mathrm{bcc}-\mathrm{Fe}$ & 63 & 63 & 63 & 61 \\
\cline { 2 - 6 } & $\mathrm{Fe}_{3} \mathrm{O}_{4}$ & 0 & 0 & 0 & 0
\end{tabular}

It is noteworthy that the amount of magnetite decreases towards deeper subsurface regions as seen by CXMS. None is detected at the air side. Nanograins of bcc-Fe evolve more rapidly at the air side than at the wheel side with heat treatment. Nevertheless, after annealing at $550{ }^{\circ} \mathrm{C}$, the amount of nanograins is almost saturated at both surfaces and no magnetite is detected.

Vibrational properties of the alloys are described by density of phonon states (DOS) that were obtained from nuclear inelastic scattering of synchrotron radiation [5]. Their evolution from the as-quenched state towards well established nanocrystalline arrangement is seen in Fig. 3a. Low energy regions (up to $14 \mathrm{meV}$ ) ex- hibit in Fig. 3b linear dependences of DOS on the energy squared $\left(E^{2}\right)$. Comparison of the data obtained from the ${ }^{57} \mathrm{Fe}_{81} \mathrm{Mo}_{8} \mathrm{Cu}_{1} \mathrm{~B}_{10}$ alloy with those corresponding to a calibration ${ }^{57} \mathrm{Fe}$ foil demonstrate a tendency of the partially nanocrystalline alloys to adopt the final structural state close to a fully crystalline one. On the other hand, moderate annealing at $370{ }^{\circ} \mathrm{C}$ resulted in structural relaxation in the amorphous phase that is very similar to the as-quenched one.

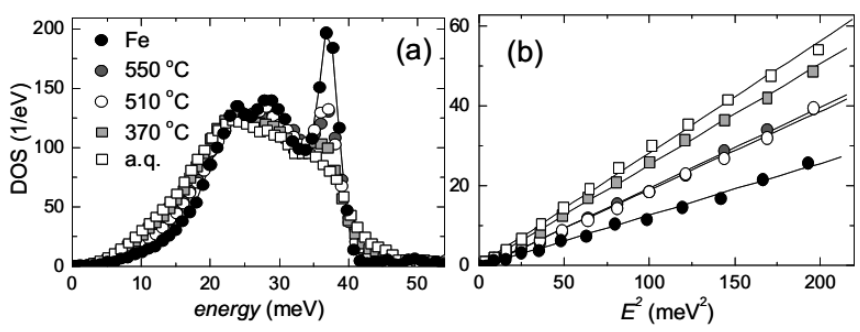

Fig. 3. DOS as a function of energy (a) and $E^{2}$ (b) for different states of the ${ }^{57} \mathrm{Fe}_{81} \mathrm{Mo}_{8} \mathrm{Cu}_{1} \mathrm{~B}_{10}$ alloy and ${ }^{57} \mathrm{Fe}$ foil.

\section{Conclusions}

We have investigated surface and bulk features of the ${ }^{57} \mathrm{Fe}_{81} \mathrm{Mo}_{8} \mathrm{Cu}_{1} \mathrm{~B}_{10}$ alloy by CEMS, CXMS, and NIS techniques, respectively. Along with nanograins of bcc-Fe, presence of $\mathrm{Fe}_{3} \mathrm{O}_{4}$ was revealed mainly in immediate $(<200 \mathrm{~nm})$ subsurface regions at the wheel side. Magnetite, as a corrosion product, might be formed due to residual humidity inside air pockets formed during the production. It has vanished after annealing at temperature higher than $510{ }^{\circ} \mathrm{C}$.

Phonon states derived from NIS experiments show that the vibrational properties of the nanograins are similar to those of a coarse-grained iron foil.

\section{Acknowledgments}

This work was supported by the research projects VEGA 1/0286/12, SK-PL-0032-12, CZ.1.05/2.1.00/03.0058, and CZ.1.07/2.3.00/20.0155.

\section{References}

[1] M. Miglierini, J.-M. Grenèche, J. Phys.: Condens. Matter. 15, 5637 (2003).

[2] S. Stankov, B. Sepiol, T. Kan̆uch, D. Scherjau, R. Würschum, M. Miglierini, J. Phys.: Condens. Matter. 17, 3183 (2005).

[3] E. Illeková, D. Janičkovič, M. Miglierini, I. Škorvánek, P. Švec, J. Magn. Magn. Mat. 304, e636 (2006).

[4] S. Stankov, M. Miglierini, A.I. Chumakov, I. Sergueev, Y.Z. Yue, B. Sepiol, P. Svec, L. Hu, R. Rüffer, Phys. Rev. B 82, 144301 (2010).

[5] W. Sturhahn, Hyperfine Int. 125, 149 (2000). 